\title{
Mechanism of Prophylaxis by Silver Compounds against Infection of Burns
}

\author{
C. R. RICKETTS, D.sC. ; E. J. L. LOWBURY, D.M. ; J. C. LAWRENCE, PH.D. \\ M. HALL, A.I.M.L.T. ; M. D. WILKINS,* A.I.M.L.T.
}

\begin{abstract}
Cummary: To clarify the mechanism by which local $\checkmark$ application of silver compounds protects burns against infection, an ion-specific electrode was used to measùre the concentration of silver ions in solutions. By this method it was shown that in burn dressings silver ions were reduced to a very low level by precipitation as silver chloride. The antibacterial effect was found to depend on the availability of silver ions from solution in contact with precipitate. Between $10^{-5}$ and $10^{-6}$ molar silver nitrate solution in water was rapidly bactericidal. The minimal amount of silver nitrate causing inhibition of respiration of skin in tissue culture was about 25 times the minimal concentration of silver nitrate that inhibited growth of Pseudomonas aeruginosa.
\end{abstract}

\section{Introduction}

The value of silver nitrate and other silver compounds in prophylaxis against infection of burns, especially with Pseudomonas aeruginosa, has been established by work in several centres (Moyer, Brentano, Gravens, Margraf, and Monafo, 1965; Cason, Jackson, Lowbury, and Ricketts, 1966; MacMillan, Hill, and Altemeier, 1967; Lowbury and Jackson, 1968, 1970; Fox, Rappole, and Stanford, 1969). Silver applied in such dressings combines with chloride in the burn exudate to form nearly insoluble silver chloride. The question arises of how bacterial infection is prevented by silver compounds in this situation. The problem has been examined in the experiments described here with the aid of an electrode that measures the concentration of silver ions in solution.

\section{Methods}

Silver Ion Concentration.-A specific ion electrode, Orion Model 94-16, was used. A calomel half-cell dipping into saturated potassium chloride solution was connected by a bridge of molar potassium nitrate in agar gel contained in flexible polyethylene tubing in order to avoid contamination of the sample under test with chloride ions. The free end of the bridge tubing and the sensitive membrane on the end of the specific ion electrode were maintained a few millimetres apart and brought into contact with the surface of the dressing, cream, or solution under test so as to complete the circuit with a Radiometer type $26 \mathrm{pH}$ meter measuring millivolts. Silver nitrate solution, $0.5 \%$, showed $466 \mathrm{mV}$; solutions of known concentration showed the theoretical change of $59 \mathrm{mV}$ for each tenfold change in concentration. The sensitivity was thus comparable with that of a $p H$ meter for measuring hydrogen ion concentration.

Inhibition of Growth of Ps. aeruginosa by Silver Nitrate.Doubling dilutions of $1 \%$ silver nitrate solution were prepared in nutrient broth containing known concentrations of sodium chloride between 3 and $10 \mathrm{mg} . / \mathrm{ml}$. A standard inoculum $(0.02 \mathrm{ml}$. of a $1: 200$ dilution of an overnight broth culture) of a strain of Ps. aeruginosa (9413) was added to tubes containing these solutions. In previous tests the strain was shown to be highly sensitive to silver nitrate. Cultures were examined for turbidity due to growth after 18 hours' incuba-

* M.R.C. Industrial Injuries and Burns Unit, Birmingham Accident Hospital, Birmingham 15. tion at $37^{\circ} \mathrm{C}$. A plate dilution test has been used in this unit as a routine method of assessing sensitivity of bacteria to silver nitrate (Cason et al., 1966).

Bactericidal Action of Silver Compounds against Ps. aeruginosa.-An aqueous suspension of Ps. aeruginosa, strain $9413\left(0 \cdot 1 \mathrm{ml}\right.$. containing approximately $10^{6}$ viable organisms per $\mathrm{ml}$.), was added to tubes containing $10 \mathrm{ml}$. of aqueous silver nitrate solution, $1 \mu \mathrm{g}$. and $0.5 \mu \mathrm{g} . / \mathrm{ml}$.; replicate experiments were made with each dilution of silver nitrate. The same inoculum was added to the supernatant removed from an aqueous suspension of silver chloride. Viable counts of Ps. aeruginosa were made on these solutions by the method of Miles, Misra, and Irwin (1938) at 1, 5, 15, 30, and 60 minutes after the addition of bacterial suspension.

Respiration of Skin Cells.-The respiration of splitthickness slices of guinea-pig ear skin containing about equal amounts of epidermis and dermis was measured as described by Lawrence (1959).

Absorption of Silver by Ps. aeruginosa Cells._- ${ }^{110} \mathrm{Ag}$-silver nitrate was mixed with silver nitrate to provide 60 counts per second per microgram of silver, well-crystal scintillation counting equipment for measurement of the radioactivity being used. Doubling dilutions of silver nitrate in nutrient broth containing $5 \mathrm{mg}$. of sodium chloride per ml. were made to span the minimal inhibitory concentration of silver nitrate for Ps. aeruginosa (strain 9413) as described above. These tubes were inoculated with this strain and incubated at $37^{\circ} \mathrm{C}$. for 18 hours. Tubes showing growth of bacteria were centrifuged, and the separated bacterial cells were washed repeatedly, first with nutrient broth and then with $0.1 \%$ aqueous silver nitrate solution as carrier. The radioactivity of the cells was measured after each washing.

\section{Results}

Silver Ions in Burn Dressings.-Silver ions in compresses soaked in $0.5 \%$ silver nitrate $\left(3 \times 10^{-2} \mathrm{M}\right)$ and applied to an exuding burned surface were quickly reduced to a low concentration by the emerging chloride; silver ion concentrations of $10^{-10} \mathrm{M}$ were recorded two days after application. Creams in a base of emulsifying wax (B.P.) showed less than their nominal concentration of silver ions when freshly made-for example, $0.5 \%$ silver nitrate cream showed ionized silver equivalent to $0.15 \%$ silver nitrate solution, and $1 \%$ silver nitrate cream showed ionized silver equivalent to $0.62 \%$ silver nitrate. Presumably substances were present in the base of the cream which combined with silver ions; nevertheless, these dressings were effective (Cason et al., 1966). Where contaminated with exudate from the burn, dressings of silver nitrate cream also showed very low concentrations of silver ions, of the order of $10^{-10} \mathrm{M}$.

Inhibition of Growth of Ps. aeruginosa.-The relationship between the concentration of silver nitrate added to a broth medium and the concentration of silver ions present after precipitation by chloride was examined in broth containing various concentrations of sodium chloride, with the results shown in the Chart. Minimal inhibitory concentrations of silver nitrate originally included in these media are shown; these end-points lie in the region $20-40 \mu \mathrm{g}$. of silver nitrate per ml., with silver ion concentrations, after precipitation 
of chloride, in the range $1-3 \times 10^{-9} \mathrm{M}$. Note that if the minimal inhibitory concentration had corresponded with the concentration of silver ions the end-points of bacterial growth would have been distributed in a vertical line on this diagram and not a horizontal line, as found. This finding suggests that the concentration of silver in all forms taken together-that is, silver ions in contact with silver chloride precipitate-determines the antibacterial activity of the medium.

Bactericidal Action of Silver Nitrate Solutions.-The percentage of the initial number of Ps. aeruginosa surviving at intervals after exposure to aqueous silver nitrate at 1 and 0.5 $\mu \mathrm{g} . / \mathrm{ml}$. (two experiments at each dilution) is shown in Table I. At higher concentrations of silver nitrate the bactericidal effect was too rapid to be measured by this method. The rate of bactericidal action was greater in the $1 \mu \mathrm{g}$. than in the 0.5 $\mu \mathrm{g}$. of silver nitrate. Supernatants removed from a precipitate of silver chloride showed no appreciable bactericidal action in 60 minutes. The concentrations of silver ions in these solutions were: $5.8 \times 10^{-6}, 2.9 \times 10^{-6}$, and $3.4 \times 10^{-6}$ molar respectively.

TABLE I.-Bactericidal Action of Aqueous Silver Nitrate Solutions

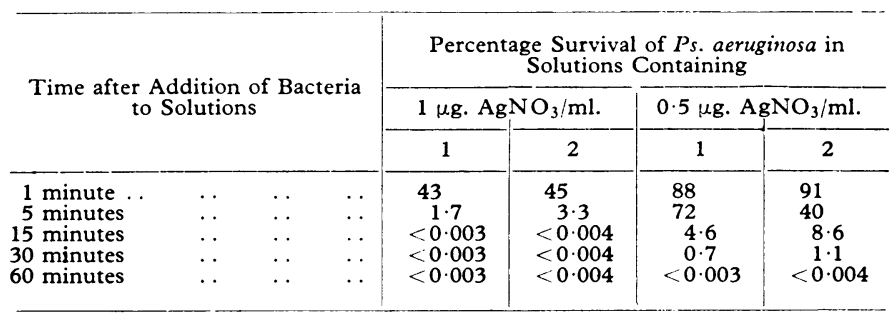

Effect on Skin Cells.-Concentrations of silver nitrate between 1 and $10 \mathrm{mg} . / \mathrm{ml}$. in the skin tissue culture medium, which contained chloride ions and serum protein, gave rise to silver ion concentrations of about $5 \times 10^{-9}$ molar (Table II). This range of concentrations of silver nitrate caused graded inhibition of skin cell respiration at a relatively constant concentration of silver ions. Thus it appeared that the con-

TABLE II.-Respiration of Skin Cells in Presence of Silver Nitrate

\begin{tabular}{|c|c|c|c|c|c|c|c|c|}
\hline \multicolumn{7}{|c|}{ Silver Nitrate Added (mg./ml.) } & \multirow{2}{*}{$\begin{array}{c}\begin{array}{c}\text { Silver Ion } \\
\text { Concentration } \\
10-9 \mathrm{M}\end{array} \\
5 \cdot 0 \\
4 \cdot 6 \\
4 \cdot 5 \\
2 \cdot 3\end{array}$} & \multirow{2}{*}{\begin{tabular}{|c}
$\begin{array}{c}\text { Inhibition of } \\
\text { Respiration (\%) }\end{array}$ \\
22 \\
39 \\
61 \\
76
\end{tabular}} \\
\hline $\begin{array}{r}1.0 \\
2.5 \\
5.0 \\
10.0\end{array}$ & $\begin{array}{l}\ldots \\
\cdots \\
\cdots\end{array}$ & $\begin{array}{l}. \\
\therefore \\
\therefore\end{array}$ & $\begin{array}{l}\cdots \\
\cdots \\
\cdots\end{array}$ & $\begin{array}{l}\ldots \\
\cdots \\
\cdots\end{array}$ & $\begin{array}{l}\cdots \\
\therefore\end{array}$ & $\begin{array}{l}\cdots \\
\cdots \\
\cdots\end{array}$ & & \\
\hline
\end{tabular}

centration of total silver and not the concentration of ionic silver is the factor determining toxicity to skin cells. Silver concentrations affecting the respiration of skin cells lie within the inset rectangular area on the Chart, and it is evident that the condition for $100 \%$ inhibition of skin cell respiration lies beyond the upper boundary of the area. Thus there is a difference of about 25 -fold in the concentration of silver causing the inhibition of cell division in Ps. aeruginosa and that causing an important degree, say $30 \%$, of inhibition of the respiration of skin cells. We chose $30 \%$ inhibition for comparison because concentrations of antibiotic and silver nitrate that cause higher degrees of inhibition have been shown to produce abnormalities in skin tissue culture and, by inference, probably interfere with the healing of burns to which they have been applied (Lawrence, 1959, 1970). The 25-fold difference in concentration may be regarded as a kind of local therapeutic index for silver nitrate as a burn dressing.

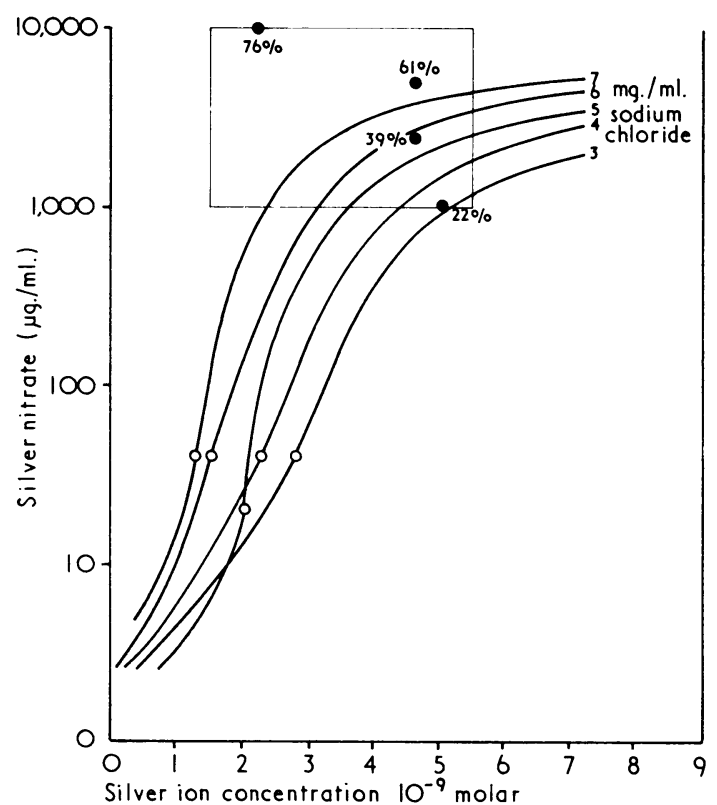

Potentiometric measurements of silver ion concentration in bacteriological broth containing silver nitrate. The curves show the effect of added sodium chloride. Growth of Ps. aeruginosa occurred at concentrations of silver nitrate lower than the open circles on each curve; higher concentrations inhibited growth. Silver ion concentrations in skin tissue culture medium (see inset rectangular area) are denoted by closed circles; the percentage inhibiton of skin cell respiration is shown.

Adsorption of Silver on Bacterial Cells.-There remains the question of how the inhibition is brought about. The binding of silver to bacterial cells was explored by growing Ps. aeruginosa in a broth medium containing a concentration of silver nitrate low enough to permit growth. The presence of ${ }^{110} \mathrm{Ag}$ enabled the adsorption of silver on to the cells to be measured. Washing with broth did not remove all the silver from the cells, but repeated washing with $0.1 \%$ silver nitrate solution completely removed the radioactivity. This showed that silver ions are reversibly adsorbed by Ps. aeruginosa cells.

\section{Discussion}

The picture we have is that a biological system, such as a bacterial or tissue culture or the surface of a burn, contains a small and rather constant concentration of silver ions in equilibrium with insoluble silver salts and complexes and, more importantly, with silver ions reversibly adsorbed by bacterial cells. This adsorption may very well occur through reversible association with $\mathrm{SH}$ groups or histidine residues in the bacterial protein. The role of a dressing appears to be to provide a ready supply of silver ions for adsorption on any new bacterial cells which may be acquired or formed so as to prevent their further growth, without greatly exceeding the total concentration of all forms of silver which is known to have a deleterious effect on skin cells.

Since all of the silver nitrate in dressings is precipitated in a short time as silver chloride it might be thought that an application of the poorly soluble chloride would be as effective as the application of a solution or a cream containing the highly soluble nitrate. But though silver chloride produces a sufficient concentration of the salt in solution to inhibit the growth of Ps. aeruginosa-for example, in culture media used for bacterial sensitivity tests-the bactericidal action of the supernatant removed from a precipitate of silver chloride is negligible and less than that of a very dilute silver nitrate 
solution-for example, $0.5 \mu \mathrm{g} . / \mathrm{ml}$. It seems probable that the outstanding prophylactic effectiveness of silver nitrate compresses is due to the high concentration of silver ions present in the dressings for a short while after each replenishment of silver nitrate solution.

The tests on Ps. aeruginosa showed that the lowest concentration of silver ions associated with bactericidal action was considerably higher than that associated with bacteriostasis. This difference can probably be ascribed in part to the shorter exposure of bacteria in the tests for bactericidal action; it is possible, too, that a higher concentration of silver ions is required for killing than for inhibition of the bacteria.
REFERENCES

Cason, J. S., Jackson, D. M., Lowbury, E. J. L., and Ricketts, C. R

Fox., C. L., Rappole, B. W., and Stanford, W. (1969). Surgery, Gynecology and Obstetrics, 128, 1021.

Lawrence, J. C. (1959). British fournal of Pharmacology and Chemotherapy, 14, 168

Lawrence, J. C. (1970). Proceedings of International Symposium on Treatment of Burns. Amsterdam, Excerpta Medica. In press.

Lowbury, E. J. L., and Jackson, D. M. (1968). Lancet, 1, 654.

Lowbury, E. J. L., and Jackson, D. M. (1970). Injury, 1, 204.

MacMillan, B. G., Hill, E. O., and Altemeier, W. A. (1967). Archives of Surgery, 95, 472 .

Miles, A. A., Misra, S. S., and Irwin, J. O. (1938). Fournal of Hygiene,

Moyer, C. A32. Arentano, L., Gravens, D. L., Margraf, H. W., and Monafo, W. W. (1965). Archives of Surgery, 90, 812.

\title{
Study on the Effects of Tablet Colour in the Treatment of Anxiety States
}

\author{
KURT SCHAPIRA, ${ }^{*}$ M.D., D.P.M. ; H. A. MCCLELLAND, $†$ M.R.C.P., D.P.M. \\ N. R. GRIFFITHS, $\ddagger$ M.B., D.P.M. ; D. J. NEWELL, $\$ M.A., PH.D., F.S.S.
}

\begin{abstract}
Cummary: Forty-eight patients with anxiety states were $\checkmark$ treated with oxazepam (Serenid-D), which was administered in tablets of three different colours-red, yellow, and green. Every patient received one week's treatment with each colour, according to a random programme. A latin square design was used to ensure complete balance between the colours and between the weeks. The patients' symptoms were categorized and then assessed by both weekly physicians' ratings and daily self-rating, which showed close agreement. Colour preference was shown on both these scales in that symptoms of anxiety were most improved with green, whereas depressive symptoms appeared to respond best to yellow. Such colour preferences, however, did not reach levels of statistical significance, except for phobias as rated on the physicians' assessment.
\end{abstract}

The results indicate that colour may play a part in the response to a drug.

\section{Introduction}

That the response to drug treatment does not merely reflect the chemical effect of the drug used has long been appreciated as an important feature in medical practice. The way in which a therapist preser ts treatment to the patient is important in this context, and there is an extensive literature on the therapeutic effects of chemically inert substances-the so-called placebo effect as discussed by Beecher (1955) and Shapiro (1960) among others. In psychiatric practice particularly, the halo effects of such factors may be of considerable importance.

The present investigation aims to examine the possible role of tablet colour in the drug treatment of patients with anxiety states, an aspect of drug treatment that does not seem to have been the subject of previous scientific inquiry. Furthermore, the study has been so designed as to permit comparison of patients' self-rating assessments with those made by the physicians.

\section{Method}

The drug used in this study was oxazepam (Serenid-D), a member of the benzodiazepine group shown by Le Gassicke

\footnotetext{
* Lecturer, Department of Psychological Medicine, University of Newcastle upon Tyne.

† Consultant Psychiatrist, St. Nicholas Hospital, Newcastle upon Tyne. Newcastle General Hospital, Newcastle upon Tyne.

‡ Formerly Senior Registrar, Department of Psychological Medicine, Newcastle General Hospital, Newcastle upon Tyne.

$\checkmark$ Professor of Medical Statistics. University of Newcastle upon Tyne.
}

and McPherson (1965) and Beber (1965) to be an effective anxiolytic agent. The dosage given was $15 \mathrm{mg}$. t.d.s. and the tablets were presented as plain (non-scored) coloured nonsugar-coated tablets. The three colours used were green, yellow, and red, and each patient received a week's treatment with each colour in a random order.

\section{Patient Group}

The 48 patients included in the trial were attending psychiatric outpatient clinics and had been diagnosed as suffering from anxiety states. Since anxiety and depressive symptoms commonly occur together, only those patients in whom anxiety was the primary affective disturbance were included. All patients had normal colour vision when tested by means of isochromatic plates (Ishihara test). In those who had been on previous medication all drugs were discontinued at least two days before the trial was begun, and for one week in respect of phenothiazins or antidepressants. Oxazepam was the only drug taken by the patients during the trial period, except for hypnotics, which were continued if they had previously been prescribed and had been beneficial.

First Interview.-This comprised a clinical assessment of the patient followed by a decision on suitability for inclusion in the trial.

Information Given to Patients.-The patients were told that the tablets which they would receive had been found to help others with symptoms similar to their own, but that the object of the trial was to determine which of the three kinds of tablets was most effective in relieving their symptoms. It was also stressed at the beginning of the trial that to keep the physician's assessment as unbiased as possible the patients should not refer to the colour of the tablets.

The evaluation of the patients' response during each week of treatment was based on a self-rating scale and on a physician's rating scale. The self-rating scale adopted was that used by Lader and Wing (1966).

\section{Self-Rating}

A completed self-rating form in which the patient's symptoms were recorded in his own words-for example, "feeling afraid," "palpitations,"-is shown (Fig. 1). Furthermore, to ensure that no relevant symptoms of anxiety had been missed systematic inquiry was made relating to the following four main groups of symptoms: 